\title{
Portões de memórias e visualidades das paisagens fúnebres: cemitérios do campo de Pelotas (RS)
}

\section{Gates of memories and visualities of the funeral landscapes: Pelotas Field Cemeteries (RS)}

\author{
Enviado em: 30/09/2020 \\ Aceito em: 05/01/2021 \\ Mauro Dillmann ${ }^{1}$ \\ Fernando Ripe ${ }^{2}$ \\ Rubens de Andrade ${ }^{3}$ \\ Lucas de Souza Pedroso ${ }^{4}$
}

\section{Resumo}

O ensaio apresenta uma pequena amostra das fotografias que compõem o extenso acervo, de imagens e dados, do projeto Cemitérios do Campo história, patrimônio e religiosidade, desenvolvido na Universidade Federal de Pelotas, que busca compreendê-los como bens culturais patrimoniais dos sujeitos que vivem, interagem e usam estes espaços na zona rural do município de Pelotas, Rio Grande do Sul. A ênfase recai sobre os aspectos materiais destas paisagens fúnebres, reveladoras de identidades religiosas e étnicas e de expressões memorais relativas aos mortos e às práticas fúnebres reinventadas.

Palavras-chave: Cemitérios do campo; Patrimônio; Memória.

\begin{abstract}
The essay presents a small sample of the photographs that make up the extensive collection, of images and data, of the project Cemeteries of the Field history, heritage and religiosity, developed at the Universidade Federal de Pelotas, which seeks to understand them as cultural assets of the subjects who live, interact and use these spaces in the rural area of the municipality of Pelotas, Rio Grande do Sul. The emphasis is on the material aspects of these funeral landscapes, revealing religious and ethnic identities and of memorial expressions relating to the dead and reinvented funeral practices.
\end{abstract}

Keywords: Field cemeteries; Heritage; Memory.

1 - Professor da Graduação e Programa de Pós-Graduação em História da Universidade Federal de Pelotas, doutor em História (UNISINOS), e-mail: maurodillmann@hotmail.com

2 - Professor da Educação Básica no município de Pelotas, doutor em Educação (UFPEL), e-mail: fernandoripe@yahoo.com.br

3 - Professor da Escola de Belas Artes da Universidade Federal do Rio de Janeiro (UFRJ), líder do Grupo de Pesquisa Paisagens Híbridas (GPPH-EBA-UFRJ), doutor em Planejamento Urbano e Regional (IPPUR-UFRJ), e-mail: andrade.rubens@gmail.com

4 - Graduando em Licenciatura em História (UFPEL), e-mail: lucas.souzapedroso@gmail.com

Revista Memória em Rede, Pelotas, v.13, n.24, Jan/Jul.2021 - ISSN- 2177-4129

periodicos.ufpel.edu.br/ojs2/index.php/Memoria 
Adentrar cemitérios, observar seus aspectos arquitetônicos, as formas das lápides, dos túmulos, das esculturas e seus simbolismos, tornam-se experiências singulares e podem possibilitar a valorização desses bens culturais e das paisagens fúnebres. Uma visita ao cemitério pode contribuir para a rememoração e culto à memória dos mortos, pois cada elemento ativa memórias, faz o passado presente a partir de evidências (simbólicas/materiais) capazes de sensibilizar quem ultrapassa seus portões, capturando fragmentos vividos e dando-lhes sentidos.

Existem em torno de cinquenta cemitérios na área rural do município de Pelotas (RS), ${ }^{5}$ número expressivo se comparado aos dois existentes na área urbana. Os cemitérios do campo possuem especificidades devido à diversidade religiosa, geográfica, histórica, espacial e religiosa (especialmente protestantes e católicos) que caracteriza o cotidiano dos grupos sociais da região. Há também as etnias alemães, pomeranas, italianas, francesas, quilombolas, indígenas e as designações de "públicos" (geridos pelo poder municipal) ou "privados" (pertencentes e administrados por comunidades religiosas ou associações locais). Cada um desses elementos são essenciais para a interpretação de como as memórias e visualidades dos cemitérios são vivenciadas pelo tecido social.

Esses cemitérios datam do final do século XIX ou início do XX. Guardam mortos de gerações de ascendentes marcados pela singularidade do modo de vida rural que, até a década de 1970, tinham sua subsistência advinda da agricultura familiar e pecuária de pequeno porte. Os cemitérios apresentam expressões de paisagens fúnebres que evidenciam identidades plurais, mas com aproximações como um modo distinto de ser e viver em pequenas comunidades rurais. São espaços ativadores de princípios de identificação coletiva e do sentimento de fazer parte de determinado contexto social local.

Este ensaio traz uma amostra de imagens, resultado da pesquisa Cemitérios do Campo: história, patrimônio e religiosidade (Departamento de História - UFPEL), que formou acervo iconográfico e de dados que nos permitem entender a dinâmica dos usos cemiteriais, os hábitos de construção das paisagens fúnebres, os modos como a morte e o morrer se revelam no cotidiano. As fotografias, de 2018 e 2019, registradas pela equipe do projeto, permitem interpretar diferentes temporalidades

50 número total de cemitérios do campo de Pelotas ainda é desconhecido, pois a pesquisa ainda não foi concluída.

Revista Memória em Rede, Pelotas, v.13, n.24, Jan/Jul.2021 - ISSN- 2177-4129 
expressas nas materialidades. São perceptíveis as marcas de mudanças nos ambientes cemiteriais, nas práticas e usos de materiais nas construções tumulares e de lápides.

A materialidade pode ser um suporte de memória compartilhada e os significados memoriais trazem a relação com a alteridade e recordação do outro. As dinâmicas fúnebres são capazes de promover a identificação do presente com o passado, uma linha de continuidade no tom memorial, mas um passado "inventado", "escolhido" e compartilhado pelas comunidades.

A seleção de imagens privilegia os efeitos de um processo objetivo e subjetivo que mediou a interpretação dos cemitérios, pois sua ordenação obedece as categorias já mencionadas (religioso/leigo, privado/público, étnico/multiétnico). Atenta-se para os aspectos visualizantes do patrimônio cemiterial e a multiplicidade tipológica no jogo de imagens que registraram portões, sepulturas, esculturas, jardins, arranjos florais, capelas e toda a cultura material que nossos sentidos foram capazes de capturar.

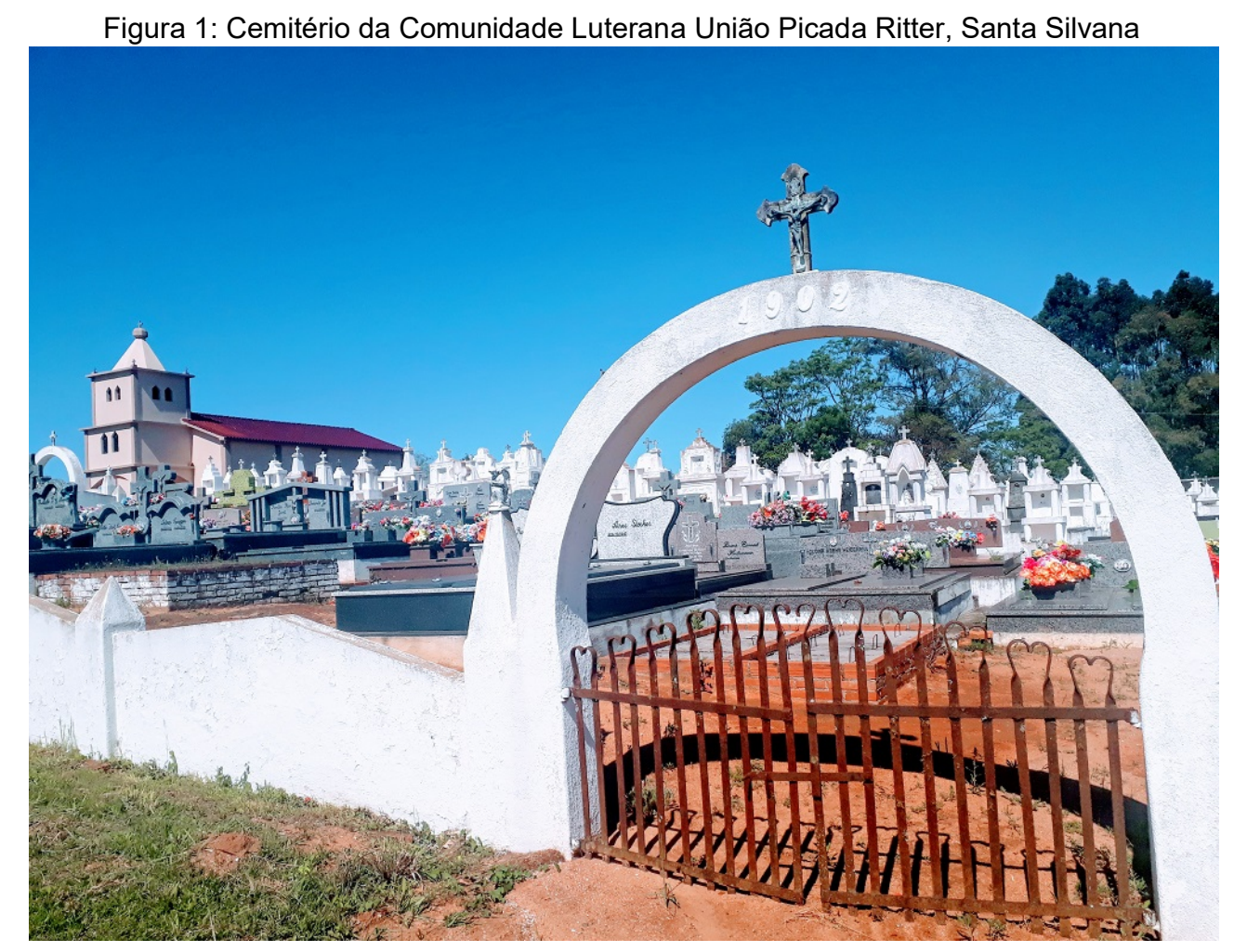

Fonte: Fotografia de Fernando Ripe, 2018 | Acervo do Projeto Cemitérios do Campo (UFPEL). 
Figura 2: Cemitério da Comunidade Santa Silvana I, Santa Silvana

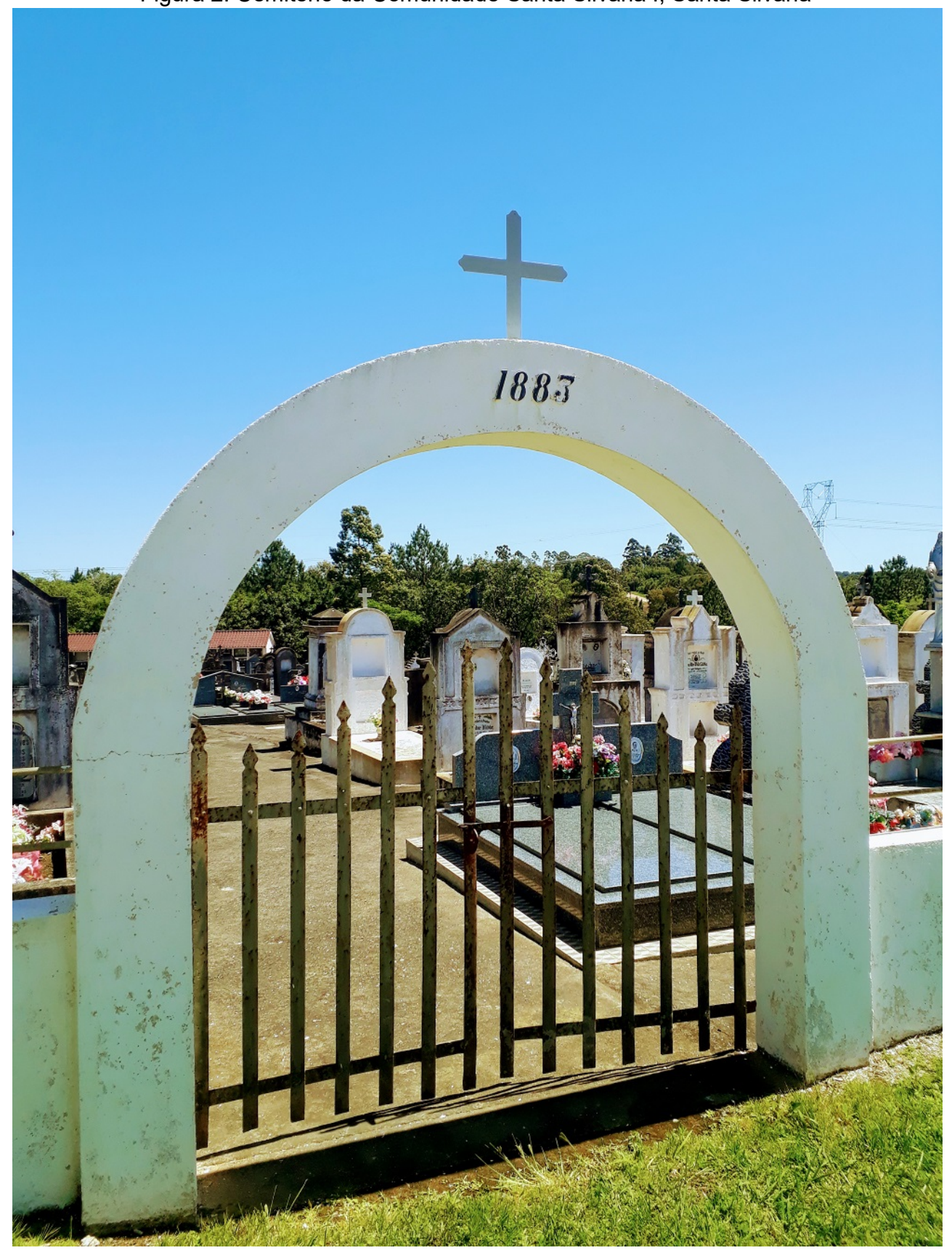

Fonte: Fotografia de Fernando Ripe, 2018 | Acervo do Projeto Cemitérios do Campo (UFPEL). 


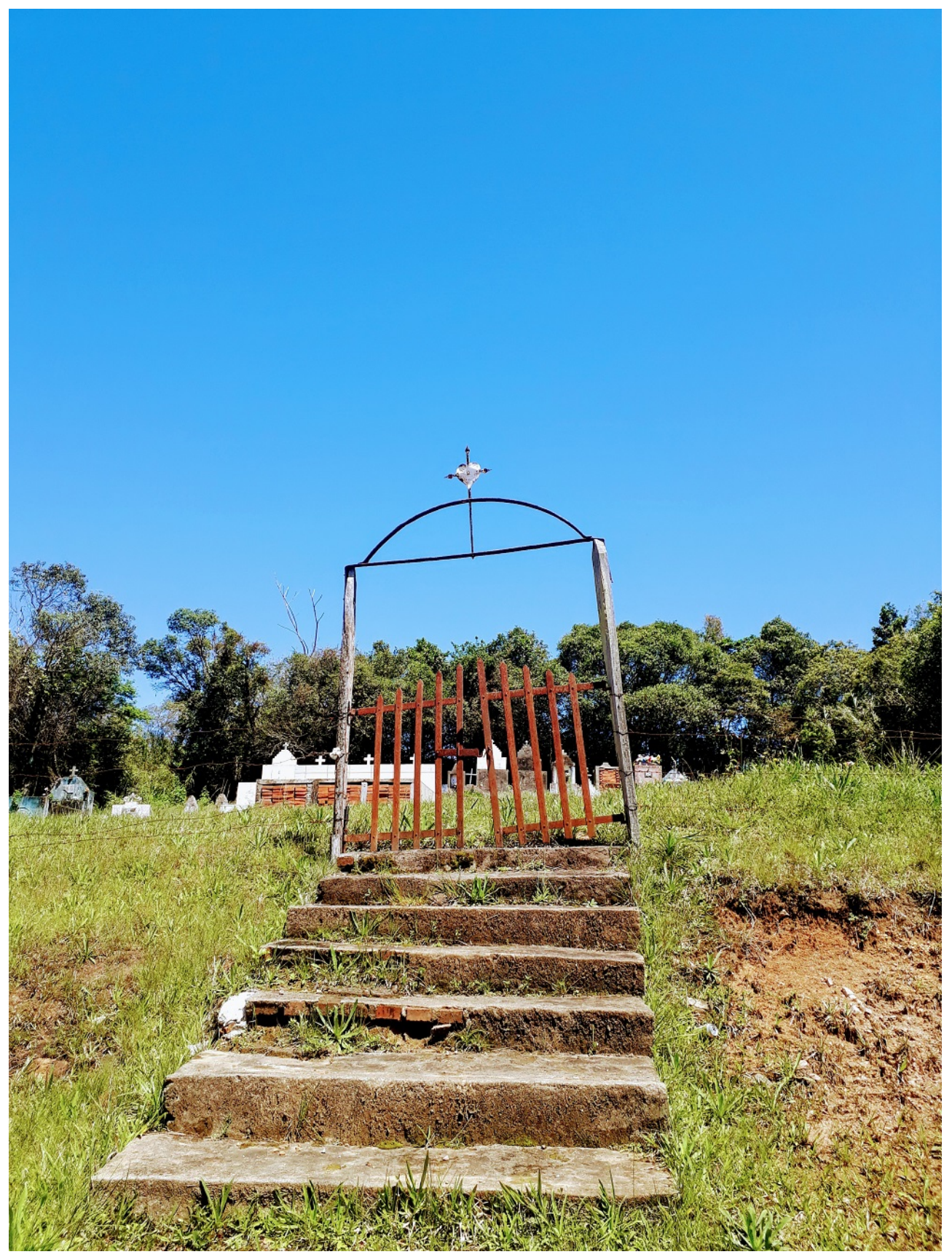

Fonte: Fotografia de Mauro Dillmann, 2019 | Acervo do Projeto Cemitérios do Campo (UFPEL). 
Figura 4: Cemitério Quilombola do Algodão, Triunfo

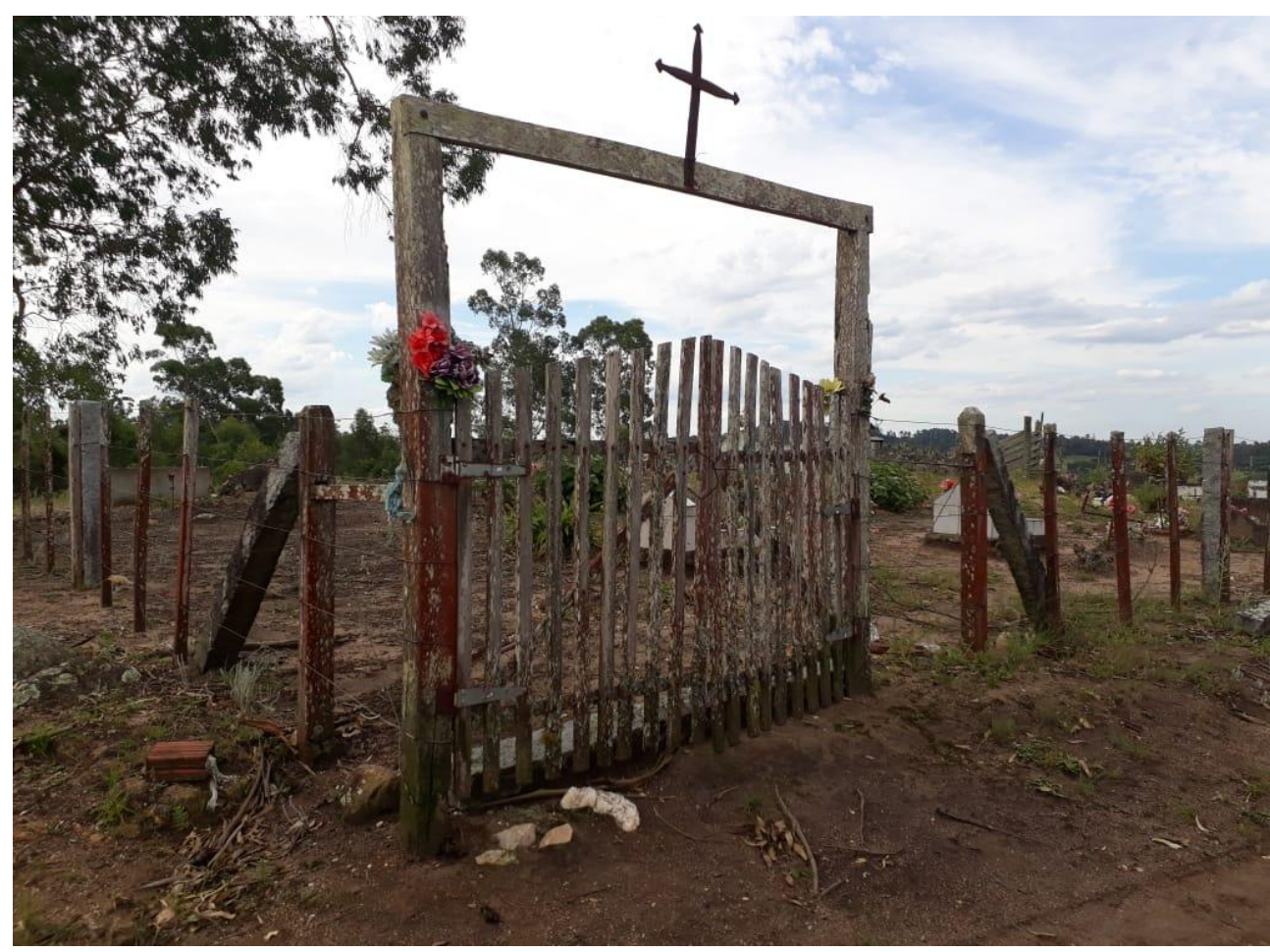

Fonte: Fotografia de Fernando Ripe, 2019 | Acervo do Projeto Cemitérios do Campo (UFPEL).

Figura 5: Cemitério da Comunidade Ascensão, Cascata

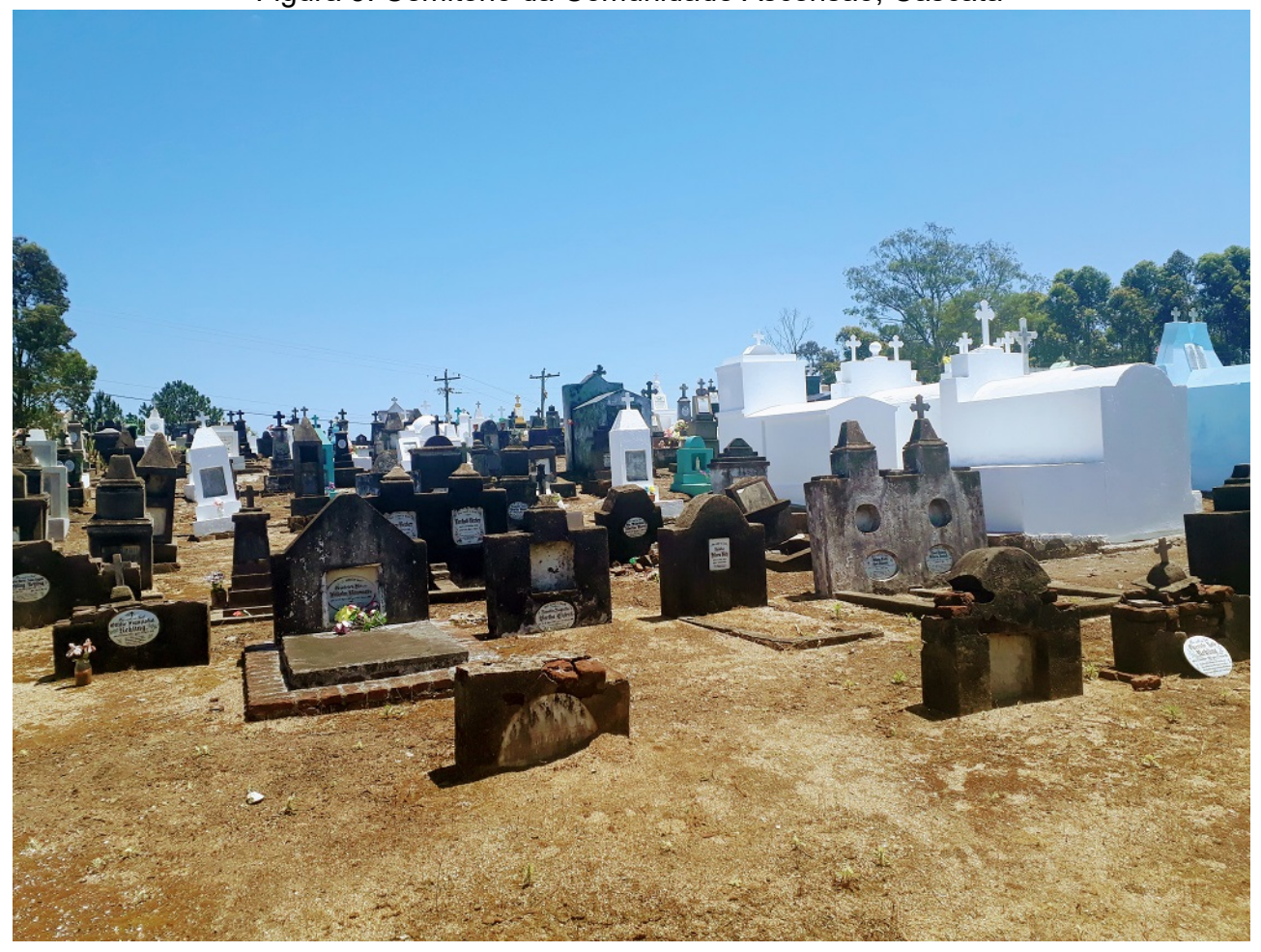

Fonte: Fotografia de Mauro Dillmann, 2018 | Acervo do Projeto Cemitérios do Campo (UFPEL).

Revista Memória em Rede, Pelotas, v.13, n.24, Jan/Jul.2021 - ISSN- 2177-4129 periodicos.ufpel.edu.br/ojs2/index.php/Memoria 
Figura 6: Cemitério da Comunidade Vitória, Cascata

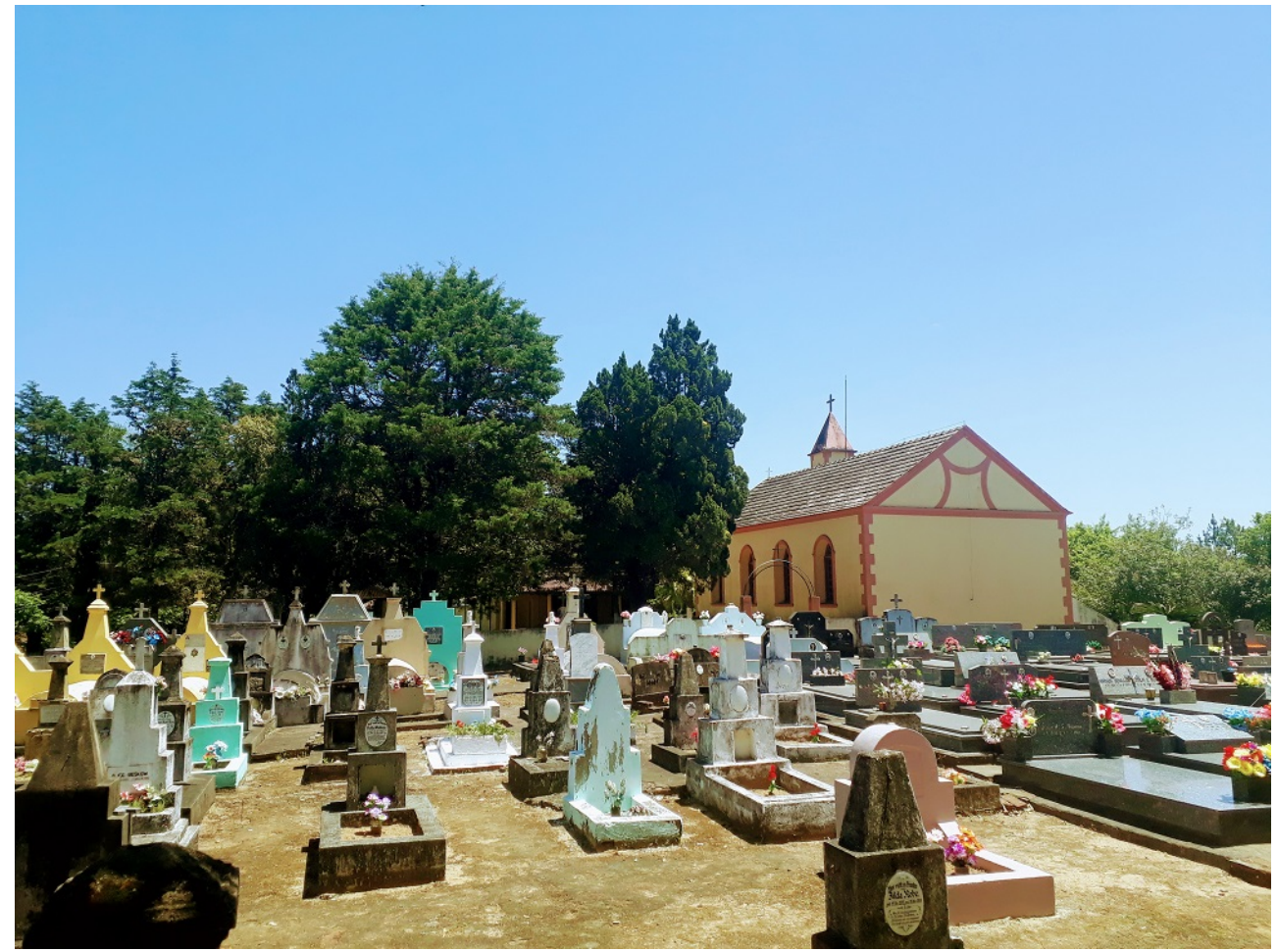

Fonte: Fotografia de Fernando Ripe, 2019 | Acervo do Projeto Cemitérios do Campo (UFPEL). 
Figura 7: Cemitério da Comunidade Evangélica Santo Antônio, Quilombo

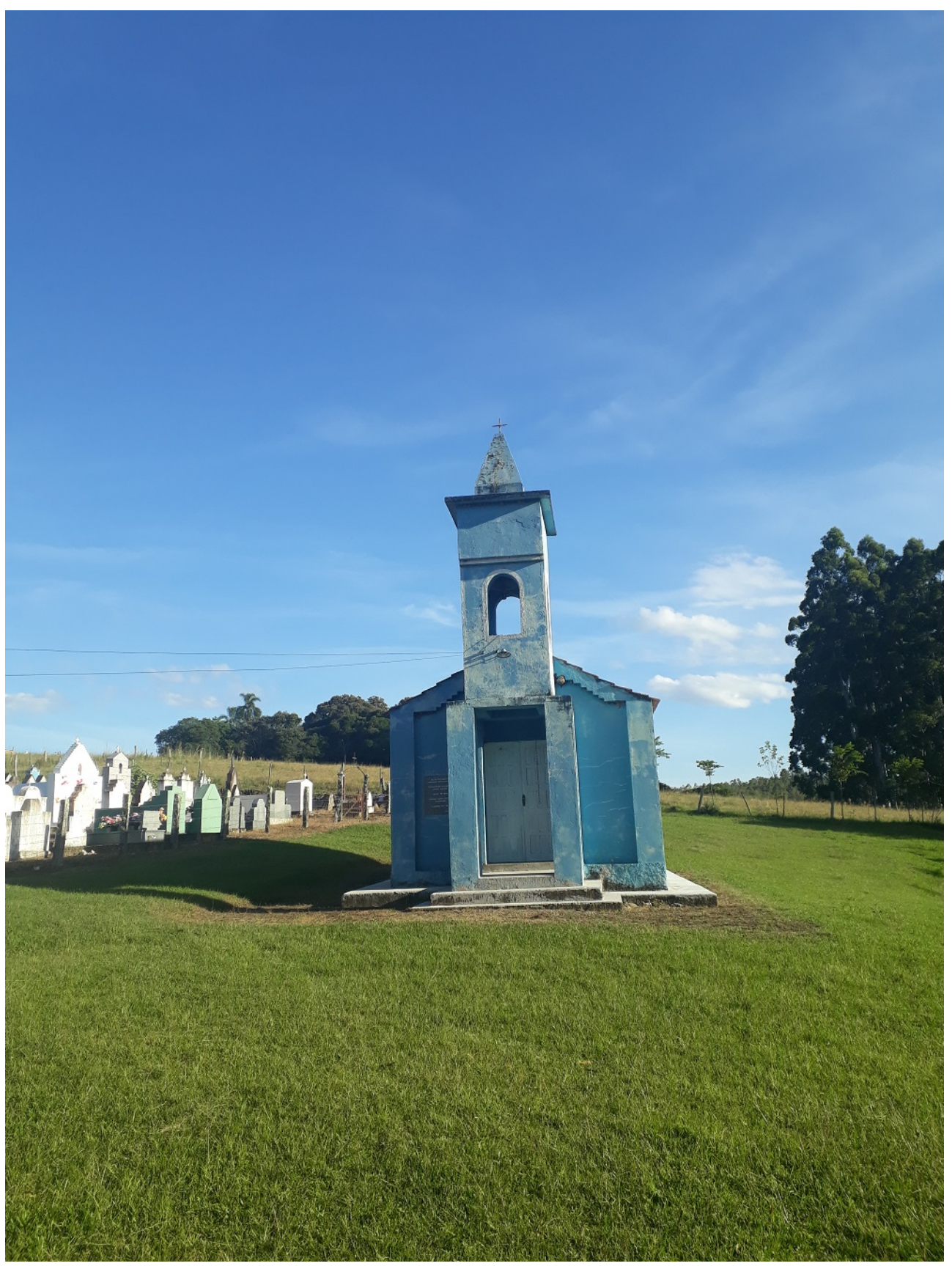

Fonte: Fotografia de Mauro Dillmann, 2019 | Acervo do Projeto Cemitérios do Campo. 
Figura 8: Cemitério da Comunidade São Pedro da Chicuta Oliveira, Triunfo

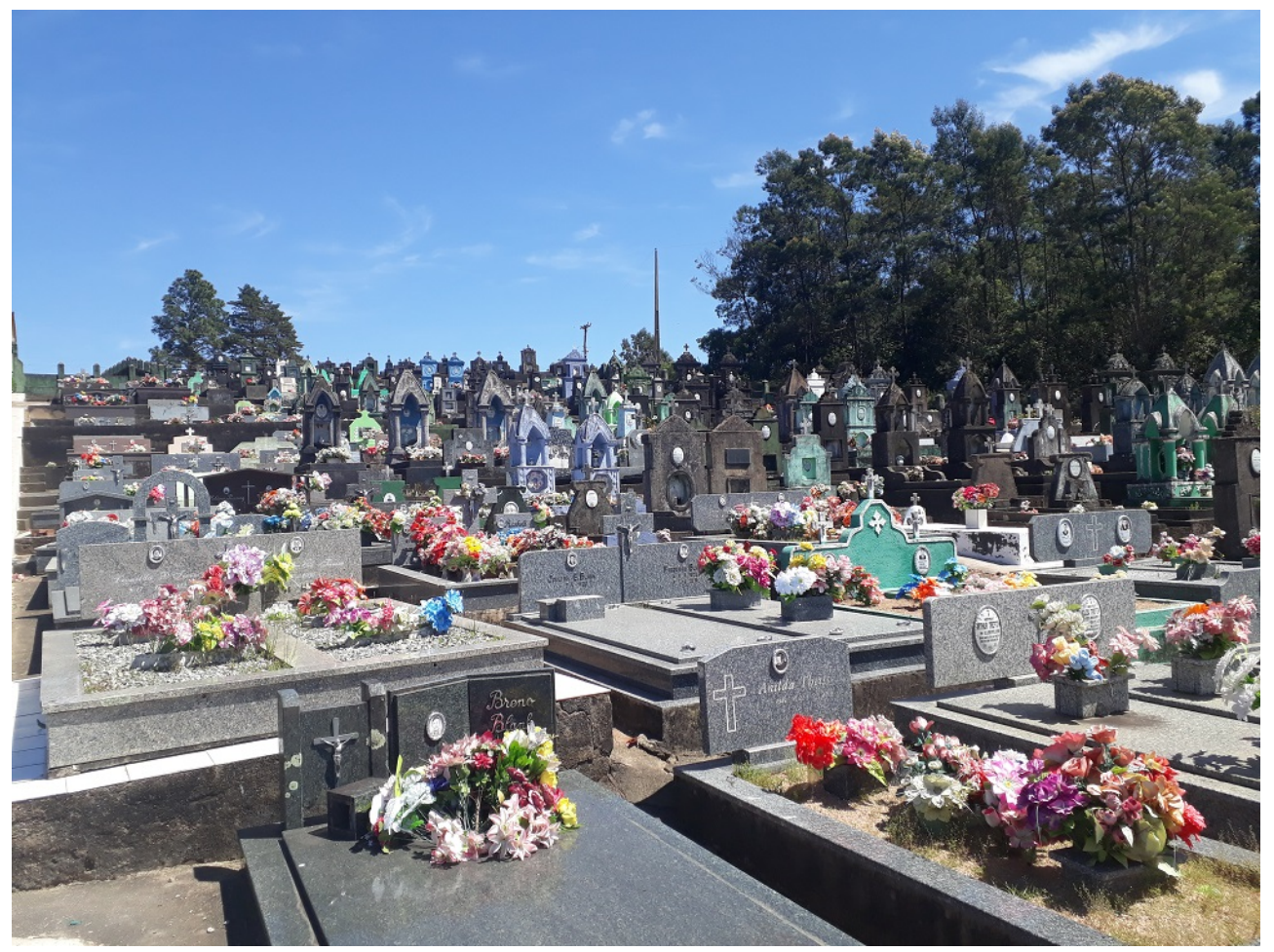

Fonte: Fotografia de Mauro Dillmann, 2019 | Acervo do Projeto Cemitérios do Campo (UFPEL).

Figura 9: Cemitério da Comunidade Luterana União Picada Ritter, Santa Silvana

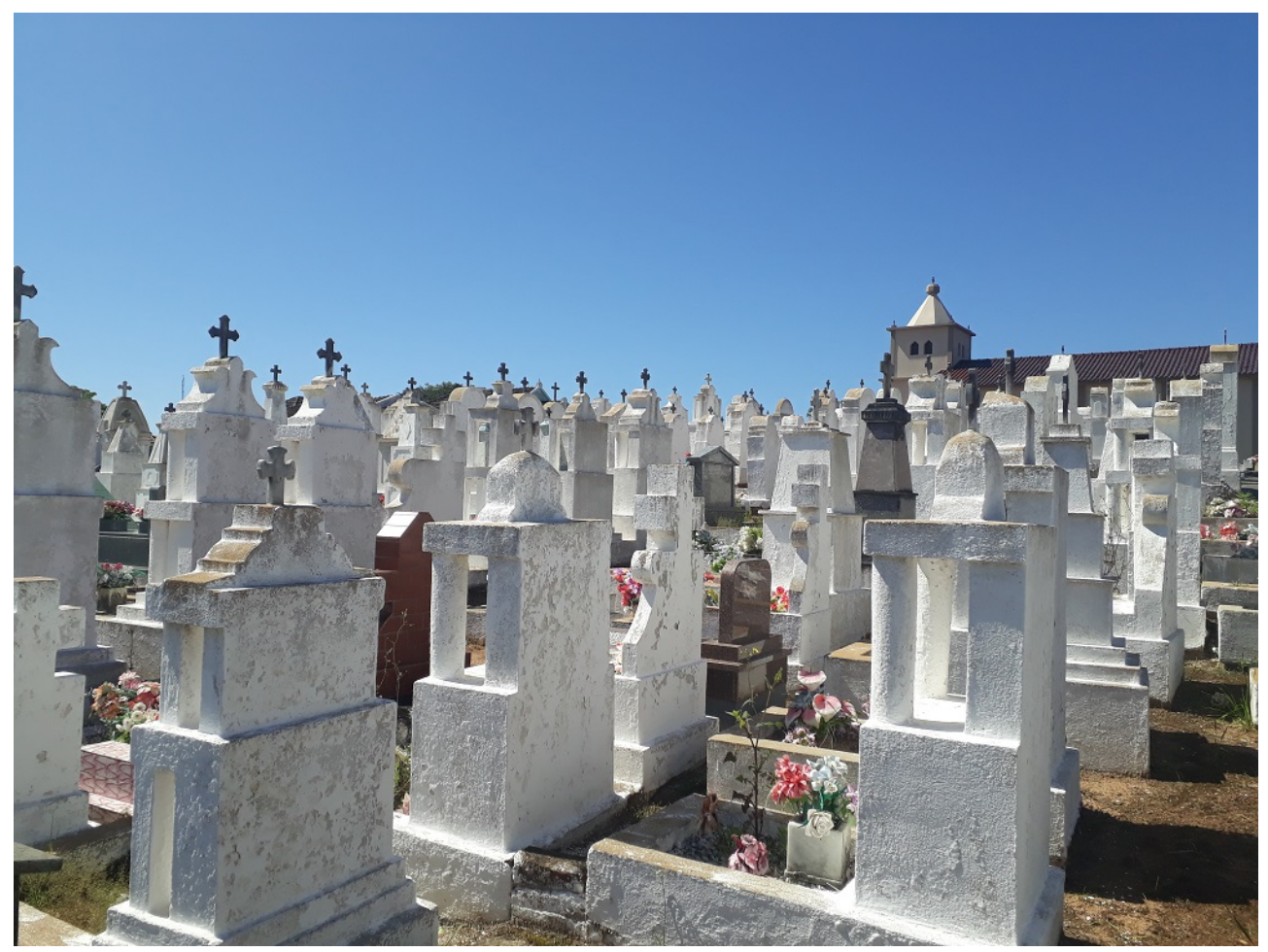

Fonte: Fotografia de Fernando Ripe, 2018 | Acervo do Projeto Cemitérios do Campo (UFPEL).

Revista Memória em Rede, Pelotas, v.13, n.24, Jan/Jul.2021 - ISSN- 2177-4129 periodicos.ufpel.edu.br/ojs2/index.php/Memoria 
Figura 10: Cemitério da Comunidade São Pedro da Chicuta Oliveira, Triunfo

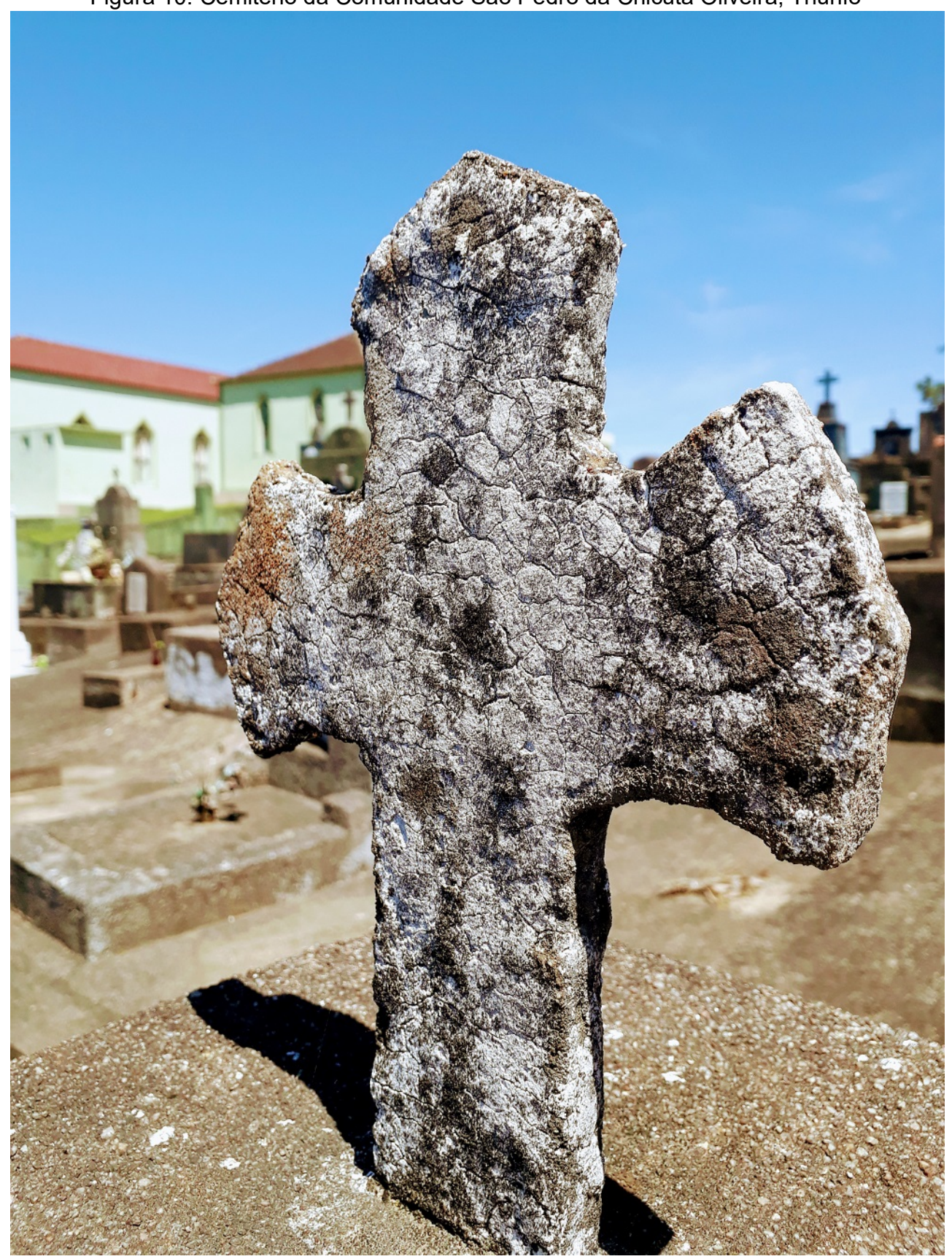

Fonte: Fotografia de Fernando Ripe, 2019 | Acervo do Projeto Cemitérios do Campo (UFPEL). 